\title{
El decreto del Congreso y el fragmento 153 de Teopompo
}

\author{
C. Schrader
}

En su famoso estudio sobre el desarrollo de la simmaquía delo-ática, Nesselhauf, tras mencionar el cambio que experimentó la política ateniense mediado el siglo $\mathrm{V}$, incide en una cuestión de relevante importancia: «En esas mismas fechas, poco después de la paz de Calias y antes de comenzar la construcción del Partenón, hubo otro acontecimiento de ca. rácter eminentemente político, cuyo significado ha sido en general desvalorizado o, al menos, no suficientemente valorado: el plan de un congreso panhelénico convocado por Atenas, que debió servirse de todos los medios, incluso de la presión, para la conservación de la alianza y, asimismo, preocuparse de justificar su política iniciada por la paz con los persas, no sólo frente a los aliados, sino, principalmente, frente al resto de Grecia» ${ }^{1}$.

No obstante, los puntos a elucidar son varios y de diversa significación, ya que nuestros testimonios sobre un congreso panhelénico proyectado por Pericles, en un momento determinado de la historia ateniense del siglo $\mathrm{V}$ a. C., residen exclusivamente en la información que suministra Plutarco en un pasaje de su biografía sobre el estadista ateniense. El texto reza (Pericles, 17):

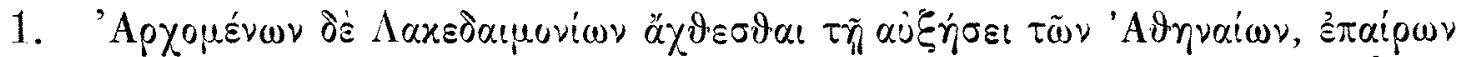

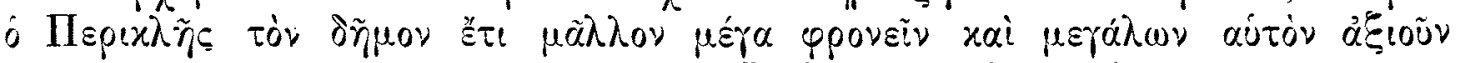

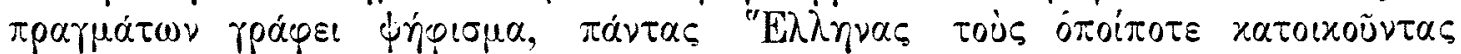

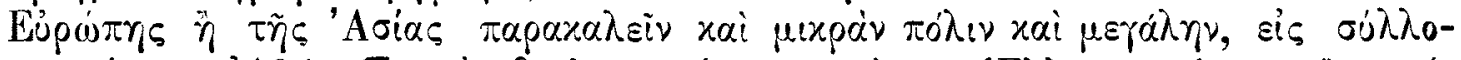

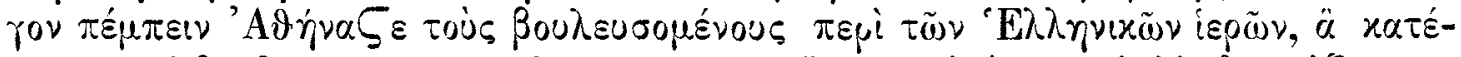

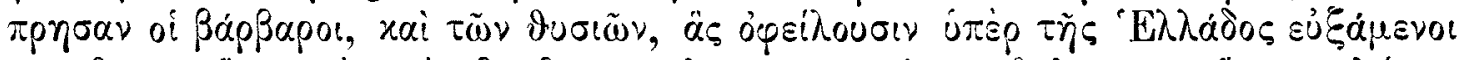

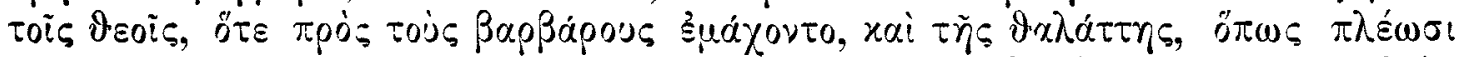

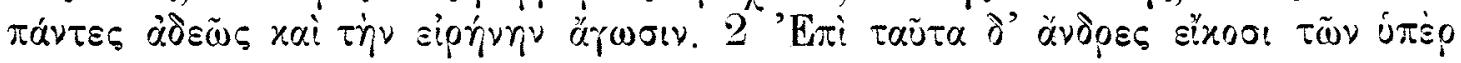

1. Nesselnauf, H., Untersuchungen zur Geschichte der delisch-attischen Symmachie, Klio, Beiheft XXX, 1933 (ed. de 1963 en Scientia Verlag, Aalen), pp. 31-32. 


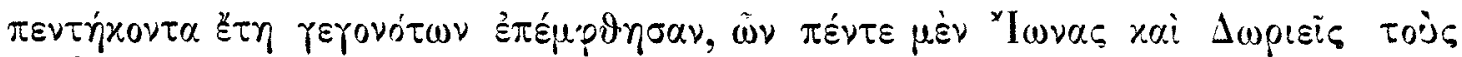

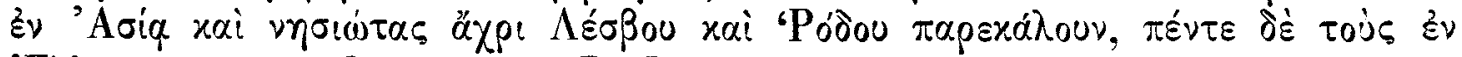

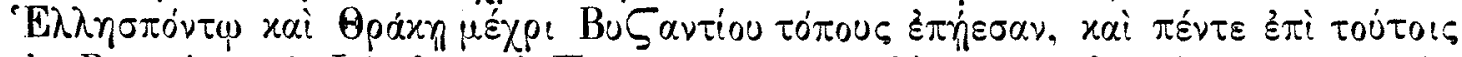

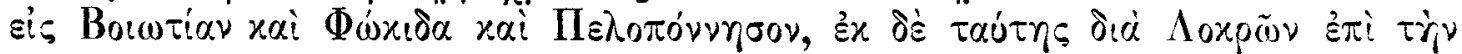

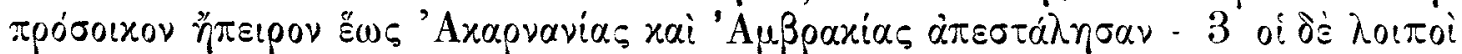

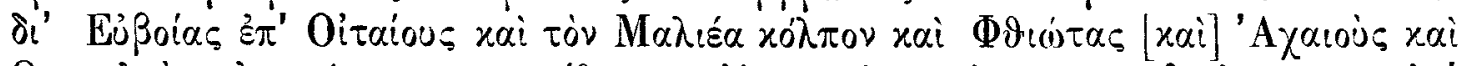

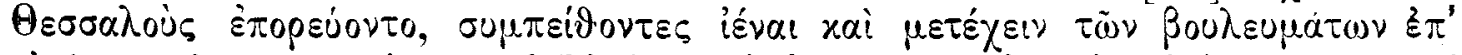

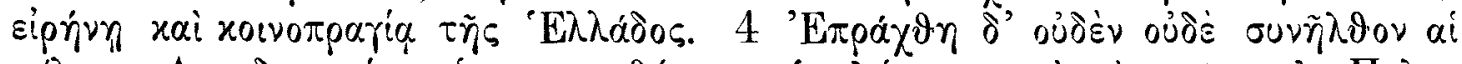

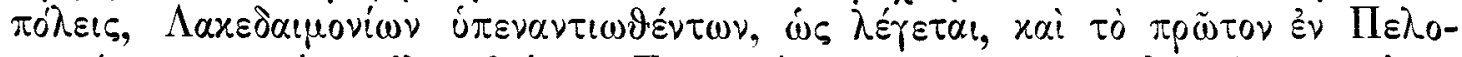

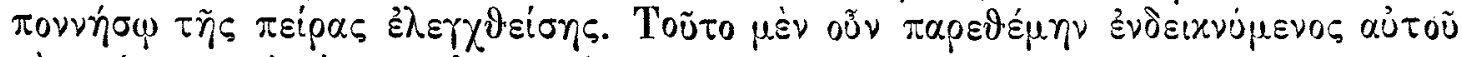

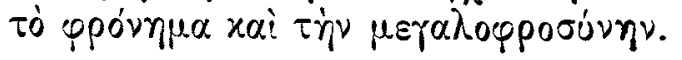

«1. Cuando los lacedemonios comenzaron a sentirse incómodos con el auge de Atenas, Pericles, para incitar al pueblo a tener mayor conciencia de su poder y a considerarse capaz de grandes empresas, hizo votar el siguiente decreto: Invitar a todos los griegos, habitasen Europa o Asia, de pequeños o grandes estados, a enviar delegados a Atenas para conferenciar en un congreso sobre los templos griegos que los bárbaros habían incendiado, sobre los sacrificios que debían a los dioses como promesa por la salvación de Grecia cuando luchaban contra los bárbaros, y sobre el mar, para que todos pudiesen surcarlo sin temor y observar la paz. 2. A tal efecto se enviaron veinte ciudadanos mayores de cincuenta años, cinco de los cuales invitaron a los jonios, dorios de Asia e isleños hasta Lesbos y Rodas; cinco se dirigieron al Helesponto y Tracia hasta Bizancio; cinco más a Beocia, Fócida y el Peloponeso, desde donde partieron, por Lócrida, en el vecino continente, a Acarnania y Ambrácida. 3. Los restante marcharon por Eubea a Etea, en el golfo malíaco, aqueos de Ftiótida (?) y Tesalia, instándoles a ir y participar en las conversaciones de paz y cooperación por Grecia. 4. Mas nada se llevó a cabo, ni las ciudades concurrieron, pues los lacedemonios se opusieron, según se dice, subrepticiamente, dado que el proyecto fue rechazado en primer lugar en el Peloponeso. Con todo, lo he mencionado para poner de relieve su propósito y señorío.»

El texto es, como vemos, bastante prolijo y su análisis debe realizarse en diversos niveles, tanto extrínseca como intrínsecamente. Gran parte de los críticos que han abordado la cuestión han considerado que este intento perícleo de convocar un congreso panhelénico responde al más inmediato resultado de la paz de Calias ${ }^{2}$, ya que, tras ésta, había desapa-

2. Una exposición crítica de la bibliografía sobre la cuestión puede verse en Meigcs, R. (The Athenian Empire, Oxford, 1972, pp. 487.495 y 598-599), en la que no aparecen registrados algunos trabajos del siglo pasado, citados por Busolt, G. 
recido el motivo fundamental por el que se había constituído la confede-

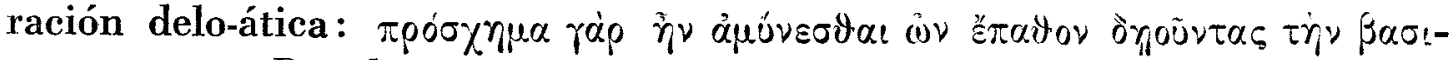

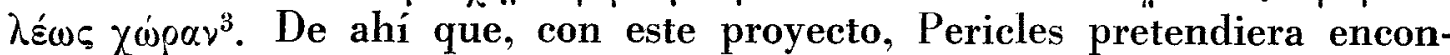
trar una nueva motivación para que los aliados siguiesen contribuyendo con el pago del pópos, al substituir una finalidad estrictamente bélica por otra de carácter pacifista. Según esto, el testimonio de Plutarco para la convocatoria del congreso sería un indicio favorable a la existencia de la paz de Calias. No obstante, la verosimilitud de la información del biógrafo no puede ser aceptada sin más, pues en algunos casos plantea unos problemas en extremo complicados.

En primer lugar es importante advertir que sólo Plutarco menciona la existencia del pretendido congreso, con lo que nos encontramos en un terreno poco firme, debido a la carencia de suficiente y contrastada documentación. El interrogante inicial que se suscita, pues, es la causa por la que esta información no aparece mencionada en fuentes anteriores a Plutarco. Y en este caso el planteamiento es proporcional al silencio que ciertos autores guardan ante la paz de Calias y la conclusión, en principio, es semejante ${ }^{4}$ ¿ ¿O hay que pensar, como KRAFT respecto a la paz ${ }^{5}$,

(Griechische Geschichte bis zur Schlacht bei Chaeroneia, Gotha, 18932, 11I, p. 346 nota 2), ni el artículo de CARY, M. («The peace of Callias», Classical Quarterly, XXXIX, 1945, pp. 87-91) entre la bibliografía posterior al trabajo de WADE GERY.

Una enumeración de los testimonios que informan negativa o positivamente sobre la paz puede hallarse en HiLl, G. F., Sources for Greek History between the persian and peloponnesian wars, Oxford, 1966, p. 344.

Sobre la problemática que la paz suscita - y que la reciente crítica favorable a su existencia tiende a justificar en base a análisis poco globales de nuestros testimoniosespero poder aportar próximamente algunas precisiones.

3. Tucídides 1.96.1. Para el significado de jyoũveas efr. Sealey, R. («The origin of the Delian Leaguen, Ancient Society and Institutions. Studies presented to $V$. Ehremberg on his 75th. birthday, Oxford, 1966, pp. 233-255) y la posterior crítica de JAckson, A. H. («The original purpose of the delian league», Historia, XVIII, 1969, pp. 12-15).

4. El silencio de Heródoto no queda paliado por su mención a la embajada de Calias a Susa en VII.151 y que únicamente daría origen a la tradición panegírica sobre la paz. Además, el historiador parece no estar garantizando la realidad de su

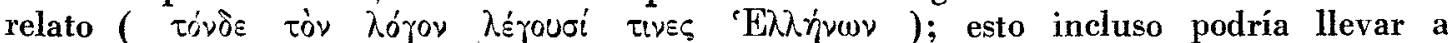
preguntarse sobre la veracidad misma de los hechos narrados, pues, como en otros tantos casos, está mencionando una información no verificada y que admite en principio porque (concordaba) con los sucesos narrados anteriormente; es decir, que este pasaje sirve de confirmación a un hecho pero él mismo no está confirmado. Respecto a VI.42.2, por otro lado, creo que la tesis de Murray, O. ('O 'APXAIOE $\triangle A E M O L '$. Historia, XV, 1966, pp. 142-156) aporta la interpretación más plausible.

Sobre Tucidides, Andrewes («Thucydides and the persians», Historia, X, 1961, pp. 15-16) sugirió que la cláusula que aparece en el tercer tratado perso-espartano

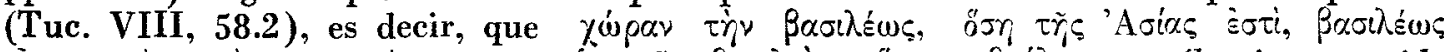

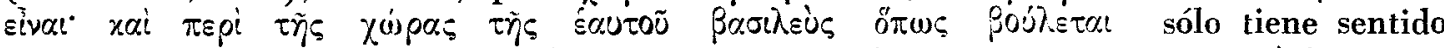
si anteriormente un tratado excluía ciertas restricciones al rey persa en Asia, tanto en territorios como en libertad de acción; es decir, si la paz de Calias contenía algunas cláusulas al respecto. Pero en VIII.58.2 se trata simplemente $r$ recelo de Persia 
que la alusión de Herodoto al congreso le hubiera supuesto tener que hacer amplias explicaciones sobre antecedentes, causas y demás circunstancias? ¿Por qué no lo menciona Tucídides? Además, tampoco aparece registrado en ninguno de los discursos o fragmentos que se nos han conservado de los oradores de tendencia panegírica a lo largo del siglo IV antes de Cristo y, dado que Diodoro no lo menciona, probablemente tampoco lo haría Eforo ${ }^{6}$. Todas estas omisiones son verdaderamente sospechosas y, de entrada, se oponen a la autenticidad histórica del congreso. Pero esto no es todo.

El propio texto de Plutarco plantea bastantes problemas, algunos de ellos muy importantes como para sustentar una valoración genuina del contenido de su información. Ante todo, en este pasaje no aparece ninguna indicación cronológica precisa; solamente que Pericles rpą̣́t $\psi \eta^{\prime}-$

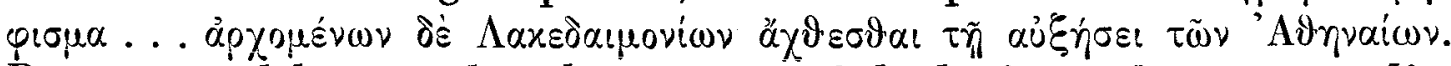
Pero estas palabras pueden abarcar un período de tiempo bastante amplio, en cuya delimitación ha existido por parte de la crítica una evidente disparidad de criterios, motivada principalmente por su predeterminada concepción del contexto histórico en que se integrase el proyecto del congreso. Así, Keulen ${ }^{7}$ lo dató poco después de 446 , sin tener en realidad una base sólida para ello, pues sus argumentaciones no resisten crítica:

1. Ante la posibilidad de que la invitación formulada por Pericles a los griegos hubiese tenido lugar antes del comienzo del Partenón $(448 / 447$ a. C. $)$, objetó que «se puede decir con mayor razón que los atenienses se habían tomado la libertad de recordar a los griegos su obligación con motivo de su propia actividad, que precisamente consistía en la construcción del Partenón». Pero esto más bien supone un planteamiento

ante Esparta y su ulterior política, ya que en los dos tratados anteriores entre ambas partes no se hace mención a esta cláusula. Cfr. Meiggs, op. cit., p. 142 n. 2 y también Stockton, D., “The peace of Callias», Historia, VIII, 1959, p. 67 nota 16: «I fail... t. see why this passage cannot equally refer to de facto, rather than de iure conditions. Some parts of Asia are not at the time under Persian control, and the Great King here asserts his right to them to avoid any misunderstandings).

Igualmente, en la Paz de Antálcidas aparece una cláusula similar (cfr. Jenofonte, Helénicas, V.1.31) y ningún tratado anterior restringía la libertad de acción de Artajerjes en su propio territorio.

5. Kraft, K., «Bemerkungen zu den Perserkriegen», Hermes, LXII, 1964, p. 170: “In dem Zusammenhang nun zu berichten, dass zu dem Zeitpunkt auch Kallias, d. h. die Athener, die Xerxes besiegt hatten, über einen Frieden verhandelten, würde der ganzen Geschichte die Wirkung nehmen, zumindest langatmige Erklärungen erfordern, dass der Kalliasfriede nicht bei Argos eine alte $\varphi_{i} \backslash \lambda i \alpha$ bestätigte oder begründete, sondern den Perserkönig einschränkte».

6. Sobre la dependencia de Diodoro respecto a Eforo para la época clásica, cfr. DREws, R., “Diodorus and his sources), American Journal of Philology, LXXXIII, 1962, pp. 383-392 у JACoBY, F., F. Gr. Hist., 70, comentario 32-3.

7. Mnemosyne, XLVIII, 1920, pp. 239 ss. 
inverso al contenido del decreto, que tenía como una de sus finalidades

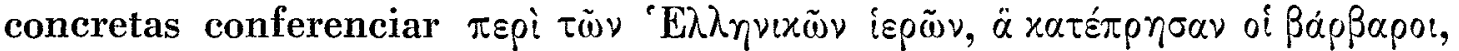
que el juramento de los griegos en Platea prohibía reedificar ${ }^{8}$. En todo caso, este argumento de KEULEN carece de demostración.

2. Y tampoco resulta fidedigno aducir que la paz con Esparta implica como fecha más adecuada para el congreso la de $446 / 5$, dado que sólo tras la conclusión de una paz entre Atenas y Esparta los lacedemonios habrían prestado inicialmente atención — con independencia de su actitud posterior- a la invitación ateniense. $Y$ no lo resulta porque también en 449/8 existía entre Atenas y Esparta un acuerdo, el armisticio firmado por cinco años, y «die Feindschaft und Rivalität, die such in dem Verhalten Spartas diesem Plane gegenüber zeigt, passt sehr gut in das Bild, das wir in dieser Zeit von Sparta haben» ${ }^{9}$.

Con argumentos más sólidos, la datación de Mattingly ${ }^{10}$ responde, sin embargo, a su cronología tardía para todos los decretos y acontecimientos históricos fechados tradicionalmente a mediados del siglo $\mathrm{V}$ a. $\mathrm{C}^{11} \mathrm{y}$ no deja de ser, aun con buenos puntos de apoyo, un intento por hacer encajar el testimonio de Plutarco en el cuadro histórico de la época según su personal datación. Así, a partir de las observaciones de SEgre ${ }^{12}$, advierte que en el texto de Plutarco, que bien podría ser el reflejo literal de un decreto registrado en piedra ${ }^{13}$, el imperio ateniense aparece dividido en cuatro distritos geográficos, lo cual podría ser un indicio de que el decreto no pudo aparecer antes de $438 / 437$, fecha en que, al unirse

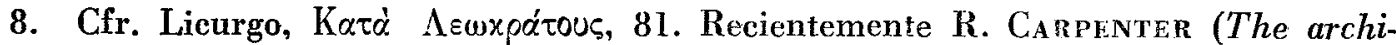
tects of the Parthenon, Londres, 1970), con argumentos arqueológicos y arquitectónicos ha abogado en favor de un nuevo templo cimónico en honor de Atena, erigido cronológicamente entre el templo inacabado que los persas destruyeron en 480 y el Partenón.

9. Nesselhauf, H., op. cit., p. 31 , nota 1 .

10. Mattingly, H. B., "The athenian coinage decree», Historia, X, 1961, pp. 159-166.

11. Mattingly, basándose en criterios paleográficos e históricos -discutibles y controvertidos-, ha tratado en una serie de artículos de fechar el apogeo del imperialismo ateniense en la primera parte de la guerra del Peloponeso (es decir, tras la muerte de Pericles) frente a la cronología tradicional, representada sobre todo por MER ITT, WadE GerY y Meiggs, quienes consideran un imperialismo perícleo a partir de la datación, entre mediados de siglo y el comienzo de la guerra peloponésica, de decretos atenienses que reflejan ese imperialismo. Uno de ellos sería el decreto del congreso teóricamente.

12. SEGRE, M., «La legge ateniese sull'unificazione della moneta», Clara Rhodos, IX, 1938, pp. 168 ss.

13. C. Coвet en 1873 («Missellanea Philologica et Critica», Mnemosyne, I, pp. 112-114) ya sugirió que Plutarco pudo haber encontrado el decreto en la colección de Crátero, puesto que hace uso de ella en otros lugares de sus biografías (cfr. p. e. Aristides 26.4). 
el distrito cario al jonio ${ }^{14}$, los distritos quedaron definitivamente establecidos en ese número. Sin embargo, ello no es totalmente cierto y recientemente BALCER ${ }^{15}$ se ha opuesto con argumentos muy sugestivos, apuntando - dentro de la línea cronológicamente «tradicional»- que en 443 el congreso de Helenotamías $(A . T . L ., \mathrm{II}, 18)$ reorganizó el imperio en cinco distritos y en $438 / 437$ (A.T.L., II, 23) se unió el distrito cario al jonio, con lo que de nuevo existían cuatro distritos tan sólo; y «aunque las listas tributarias atenienses anteriores a 433 a. C. no contienen epígrafes por distritos, el Decreto Monetario y la propuesta de Clinias ${ }^{16}$ indican una organización imperial en cuatro distritos para el período comprendido entre hacia 449 a. C. y el decreto del congreso» ${ }^{17}$.

Sin embargo, la inclusión del proyecto del congreso en el contexto histórico del siglo $V$ no es tan lógica en una fecha tardía como en una temprana. $Y$, sintomáticamente, su cronología depende en apariencia directamente de la evaluación histórica de la paz de Calias. Así MATtingly, respecto a la preocupación espartana ante el crecimiento del poder ateniense, sugería: « ¿Pero no se acomoda mucho mejor a los años treinta? La frase de Plutarco sugiere el comienzo del proceso que iba a llevar inexorablemente a la guerra total, haciéndose eco significativamente del lenguaje de Tucídides a este respecto. Este arguyó que el temor de Esparta al creciente poderio de Atenas fue lo que en realidad motivó las hostilidades en 431 a. C.» ${ }^{18}$. Esto es cierto, y más al considerar que los dos parágrafos anteriores en el texto de Plutarco versan sobre el absoluto predominio de Pericles en Atenas a partir del ostracismo de Tucídides (Plutarco, Pericles, 14.5), pero también ese recelo que sentía Esparta ante Atenas tiene su justificación hacia $449 / 8$ por los intereses lacedemonios en Grecia central ${ }^{19}$.

En realidad, la datación del congreso ha respondido, salvo en este caso, a la aceptación histórica de la paz de Calias. Y así, para Mattingly no existe dependencia del congreso con respecto a la paz, porque no admite la existencia de un tratado entre Atenas y Persia a mediados del siglo $\mathrm{V}$ y sí, en cambio, la paz de Epílico en $424 / 3^{20}$. Por ello, el decreto

14. Cfr. Meritt, B. D.; W Tribute Lists, Princeton, II, 1939, 23.

15. Martin Balcer, J., "Separatism and Anti-separatism in the Athenian Empire (478-433 B. C.)): Historia, XXIII, 1974, p. 37.

16. Cfr. Meiggs, R. y Lewis, D., A selection of greek historical inscriptions (to the end of the fifth century), Oxford, 1971 (reimp.), números 45 y 46.

17. BALCER, Ibid

18. Matringly, H. B., art. cit., p. 160.

19. Cfr. Beloch, K. J., Griechische Geschichte, Estrasburgo, 1914, pp. 178-183 y supra nota 9.

20. Cfr. Mattingly, H. B., “The peace of Kallias», Historia, XIV, 1965, p. 276. 
del congreso no podía ser fechado con posterioridad a esa fecha - ya en plena guerra peloponésica-, ni, por las razones apuntadas, inmediatamente después de 449/448. De ahí que, a juicio de Matringly, una fecha intermedia sería la adecuada ${ }^{21}$.

Por su parte, para la crítica que acepta la existencia de la paz en 449/448, el decreto - que, según esta línea, la justifica- sólo puede ser datado con inmediata posterioridad a esa fecha ${ }^{22}$. En este sentido resulta reveladora la opinión de MEIGGS: "the decree is not dated, but it makes good historical sense inmediately after the peace of Callias, when Athens needed a new sanction for what was becoming an Athenian Empire» ${ }^{23}$. Pero, ¿sólo porque aparentemente se explica históricamente tras la paz de Calias debe ser fechado tras ella? ¿Y si ya existen indicios para desestimar la realidad histórica de la paz? Desde luego, las palabras que preceden al texto del decreto no ayudan a sustentar una cronología semejante $^{24}$; y pensar que «the indication of date may be Plutarch's personal assumption or it may come from the commentary on the inscription» ${ }^{25}$, en la que se diría que Esparta se opuso, es algo en principio inconsistente; por la misma razón cabría pensar que el biógrafo, si hubiese visto registrado un documento semejante, hubiera indicado su procedencia como hace en otras ocasiones ${ }^{26}$. Ahora bien, ¿por qué este testimonio debe basarse forzosamente en una inscripción genuina del siglo $\mathrm{V} o$ en una fuente posterior que reflejara literalmente su contenido? En realidad, el texto de Plutarco conlleva una serie de características que parecen impli-

21. Sobre la relación que establece entre los Propíleos de Mnesicles y el congreso, cfr. Historia X, 1961, p. 163 (y notas 67-69): "When the Congrees failed Athens had to consider her rebuilding problems alone. Now the great Periclean schemes were inaugurated in 448-7 B. C., when work began on the Parthenon. Does this force us back to the ortodox date for the Congress Decree? I do not think so. The Parthenon can and should be separated from the plan envisaged in the Congress Decree... Menesikles' Propylaia perhaps provides us with our clue. It was begun precisely in 437-6 B. C.». En contra de este argumento, efr. MeritT, B. D. y W WDe GerY, H. T., "The dating of documents to the mid fifth century-II», Journal of Hellenic Studies, LXXXIII, 1963 , p. 107.

22. Así, Beloch, Griechische Geschichte, II, I, p. 178 s. y Wade GerY, Journal of Hellenic Studies, LII, 1932, p. 216 s. y nota 47, entre otros.

23. Meiggs, R., The Athenian Empire, pp. 512-513 (la cursiva es mía).

24. WIlamowitz (Aristotheles und Athen, II, p. 340, nota 15) veía en el

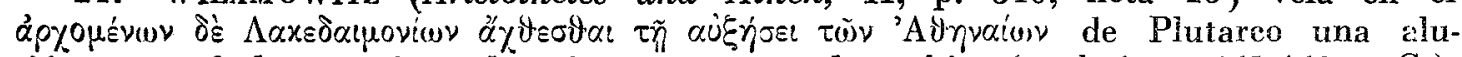
sión a una fecha anterior a la primera guerra peloponésica (es decir, a 461-460 a. C.), admitiendo una relación entre esas palabras y Esquilo, Euménides 920.

25. MEIGGS, Ibid.

26. Por ejemplo en Cimón, 13.5 (tras referirse a los límites impuestos a Persia tras la paz de Calias y a la disconformidad de Calístenes con esas cláusulas):

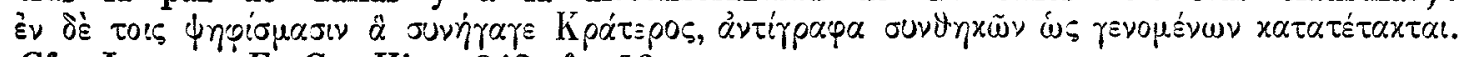
Cfr. JACoBY, F. Gr. Hist., 342, fr. 13. 
car, como apuntó SEAGER ${ }^{27}$, que se trata de una falsificación posterior de la que el biógrafo se haría eco.

Una serie de datos indican a primera vista que Plutarco desde $\pi \alpha \dot{\nu} \tau \alpha \varsigma$

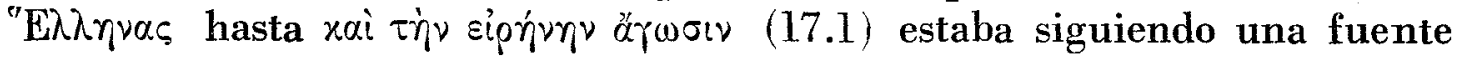
epigráfica :

1. Existe una clara oposición verbal entre las formas que aparecen en este pasaje y el punto siguiente, con predominios de infinitivos de presente en voz activa ( $\pi \alpha \rho \alpha \pi \lambda \varepsilon \tilde{\imath} \nu$ y $\pi \varepsilon ́ \mu \pi \varepsilon \iota \nu)$.

2. En los apartados 2 y 3 se hace hincapié en el número de mensajeros que debían llevar las invitaciones atenienses del congreso a los restantes estados griegos - con detalles sobre las rutas a seguir-, así como el límite de edad concreto de los mismos. Y esto coincide con similares referencias en algunos decretos atenienses fechados en el siglo $\mathrm{V}^{28}$ :

a) Coincidencia en el envío de mensajeros.

1. Decreto monetario (fechable quizá entre $450 / 446)^{29}$.

$$
\begin{aligned}
& -\mathrm{A}-
\end{aligned}
$$

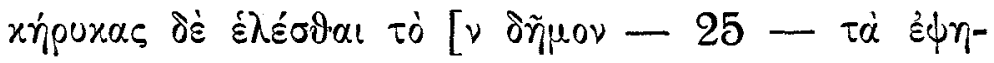

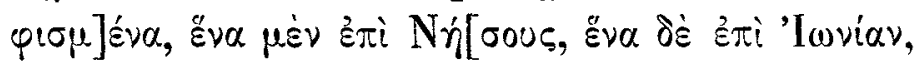

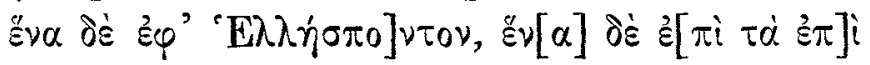

$$
\begin{aligned}
& \text { Epaixns. }
\end{aligned}
$$

27. SEAGER, R., «The Congress Decree: some doubts and a hypothesis», Historia, XVIII, 1969, pp. 129-141. Con posterioridad, Bosworth («The Congress Decree. Another Hypothesis), Historia, XX, 1971, pp. 600-616), llegó a conclusiones similares a las de Seager, es decir, a establecer la falsedad histórica del congreso panhelénico; no obstante, su camino fue diferente al considerar la posible similitud entre el decreto atribuído a Pericles y el congreso de Corinto convocado por Filipo en 338-337 a. C.

28. Cfr. BALCER, art. cit., p. 37, para un cuadro comparativo entre las rutas del decreto sobre el congreso y las de los decretos Monetario, de Clinias y de Tudipo. No obstante, las rutas mencionadas en el texto de Plutarco no coinciden estrictamente con los distritos del imperio ateniense, pues Rodas aparece incluída en el distrito isleño, Bizancio en el tracio y Eubea no aparece determinada; en cambio, en las listas fiscales están incluídas, respectivamente, en los distritos jonio-cario, helespóntico (con problemas) e isleño.

29. Cfr. Meiggs-Lewis, op. cit., núm. 45, pp. $111-117$ y Robinson, E., «The athenian currency decree and the coinage of the allies», Hesperia, Suppl. 8, 1949, pp. $324=330$. 
Atenas y sus dioses, tal y como revela un pasaje muy importante del Ión de Eurípides ${ }^{34}$.

No obstante, el ya mencionado análisis de SEAGER puso en claro que el contenido del decreto tenía poca consistencia respecto a la finalidad que se pretendía y que, en muchos aspectos, resultaba sorprendente. El programa que los emisarios debian presentar a los griegos y que, cuando el congreso estuviese reunido, debía discutirse, era triple. Se iba a tratar en él :

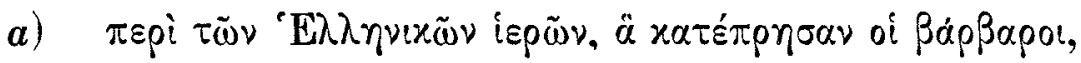

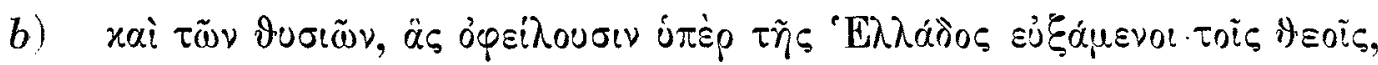

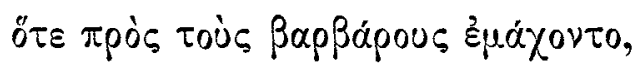

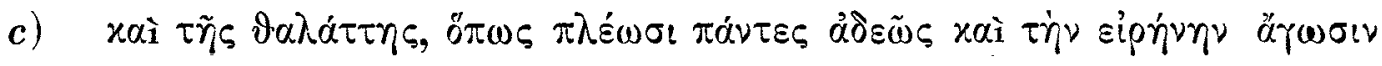

Pero, ¿qué se iba a discutir sobre los templos? Salivo en Atenas, en muy pocos lugares de Grecia fueron destruídos templos por los persas y sólo poseemos tres testimonios en ese sentido ${ }^{35}$. Además, pretender invitar a estados que habían sido filopersas durante las guerras médicas a un congreso en que se trataría un tema semejante hubiese resultado una maniobra política muy poco adecuada para conseguir una cooperación de todos los estados griegos con fines pacifistas.

E igualmente el segundo punto, el relativo a los sacrificios debidos a los dioses, suponía una ofensa para esos estados, en tanto que carecía del más mínimo interés para aquéllos que, no habiendo tomado parte en la guerra, iban ahora a ser convocados. Así, no me parece correcta la observación de MERITT y WADE GERY al indicar que «the Congress was to have three items on its agenda. Items 2 and 3 imply that peace (i. e., la paz de Calias) has been recently concluded: item 2 refers to the war in

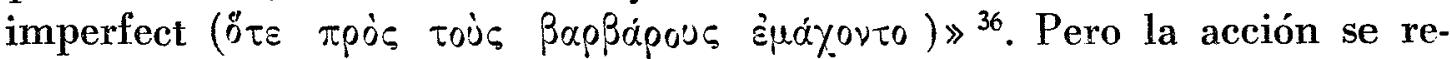
fiere a un hecho que todavía no ha llegado a su término (ópsinovotv), a partir de un momento determinado ( $u \dot{\xi} \xi \dot{\alpha} \mu \varepsilon v o t$ ), acaecido en un contexto más amplio ( $\varepsilon_{\mu} \alpha_{\alpha} \chi_{0 \nu \tau o)}$ ). Y que este imperfecto se refiere a las

34. Vv. 1581.7 ( $\pi$ aiঠ̋s se refiere a los atenienses): oi $\tau \tilde{u} y \delta \hat{\delta} \varepsilon \delta^{\prime} \alpha \tilde{U}$

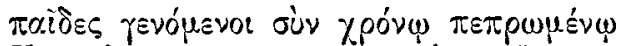

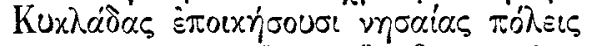

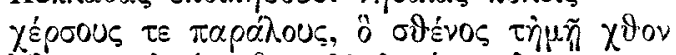

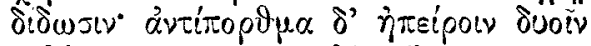

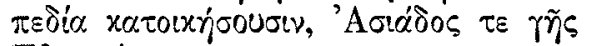
Evpoutias $\tau \varepsilon$.

35. Cfr. Herodoto VI.19.3, VIII.33; Pausanias X.35.2.

36. Meritt, B. D. y Wade Gery, H. T., art. cit., p. 107. 
guerras médicas resulta evidente: fue durante las guerras médicas cuando prometimos algo que todavía tenemos que cumplir; en un desarrollo temporal impropio, o por lo menos extraño, de una transliteración exacta de un documento inscrito en piedra:

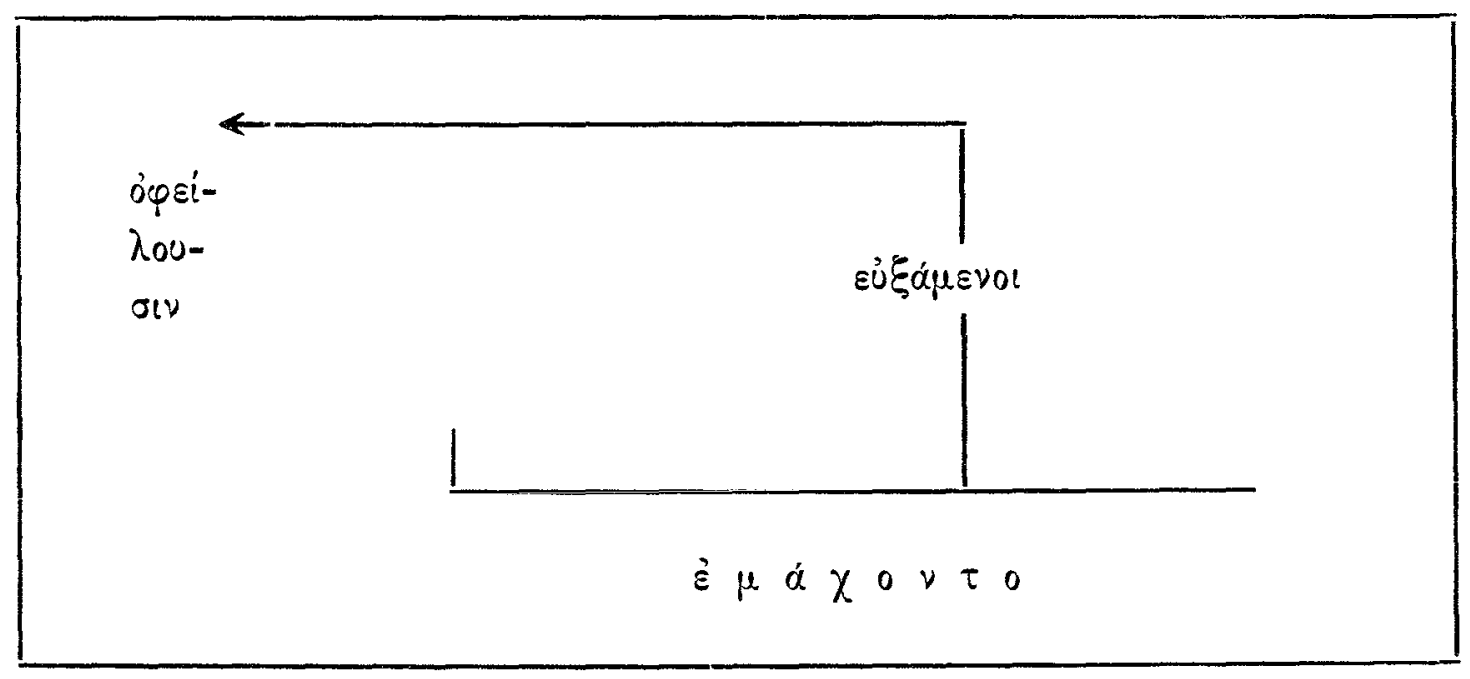

El tercer punto a discutir era el de la libertad del mar; y es el más problemático. Se ha pensado que con esta cuestión Pericles pretendía que, en la reunión a celebrar, los griegos se comprometiesen a seguir costeando los gastos de mantenimiento de la flota ateniense para conservar el mar libre de piratas, dado que la paz de Calias había puesto fin a la guerra con los persas. En teoría esto debía interesar comercialmente a la mayoría de asistentes con actividades navales en juego, pero curiosamente hasta el siglo IV a. C. no existe evidencia, en las discusiones políticas intergriegas, para semejante tema de debate. Y, como hizo notar SEAGER ${ }^{37}$, «indeed it is hard to see how the subject could have arisen before the development of the notion, if not the name, of the Common Peace». Mientras que durante todo el siglo $\mathrm{V}$ los debates sobre limitaciones navales se expresan bilateralmente ${ }^{38}$, cuando Filipo comenzó a codiciar la supremacía maritima, la libertad del Egeo se convirtió en un tópico político aparecido por vez primera con una cláusula al respecto en la paz de Filócrates.

Con todo, la crítica favorable a la paz de Calias ha visto en las palabras

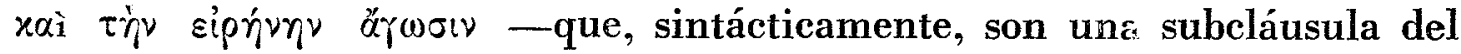
punto tercero a discutir - una referencia contemporánea, como una trans-

37. Art. cit., p. 132.

38. Cfr., p. e., Tucidides IV.118.5 (armisticio entre Atenas y Esparta por un año):

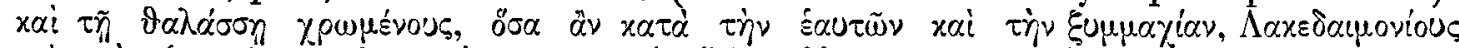

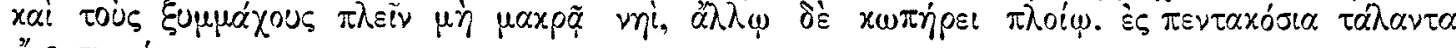

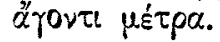




\section{SCHRADER}

literación directa de la inscripción de la que Plutarco $\longrightarrow$ su fuentedebió tomar el texto ${ }^{39}$. Sin embargo, el sintagma y sus elementos plantean ciertos problemas:

1. Si Plutarco se basó en un decreto grabado en piedra que él mismo contempló o en una fuente literaria que transcribió literalmente una inscripción -fuese o no la Colección de Decretos de Crátero-, ésta no debía ser genuina del siglo $\mathrm{V}$, sino una copia posterior, pues, como demostró KEIL ${ }^{40}$, el término siprín no indica propiamente «tratado de paz» hasta $387 / 386$.

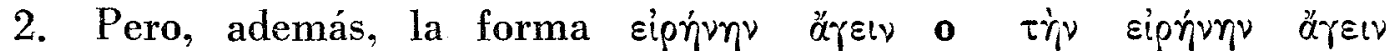
—que no aparece en inscripciones áticas de los siglos V y IV - se diferencia en su significado por la presencia del artículo: «estar en paz»/ «observar los términos de una determinada paz». Los testimonios para el primer caso son numerosos en la literatura de los siglos $\mathrm{V}$ y IV ${ }^{41}$, en tanto que, para el segundo, el primer autor que denota el contraste existente con

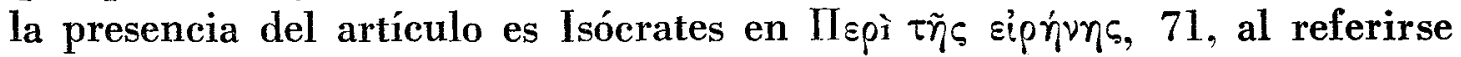
a la paz que puso fin a la llamada «guerra social»:

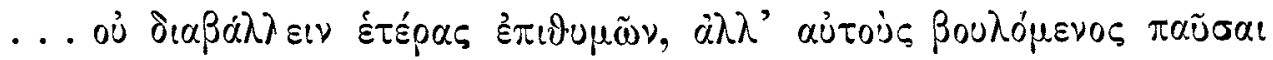

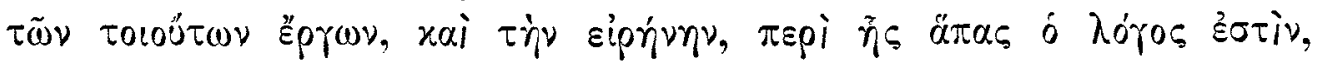

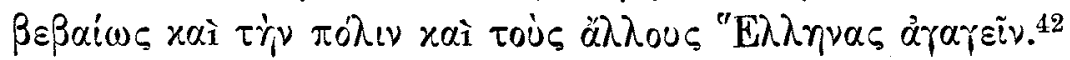

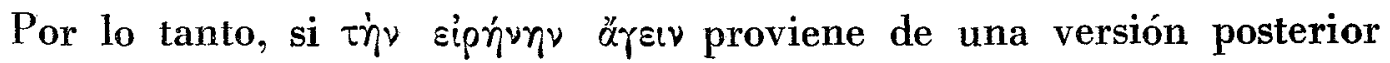
a un posible decreto del siglo $\mathrm{V}$, ¿hay que entenderlo como una referencia a la paz de Calias? Lingüísticamente podria ser así, pero si el congreso fuese verdadero históricamente, la intención de Pericles al convocarlo hubiese tendido a que un acuerdo bilateral - la paz de Caliasse convirtiese en una xotvì sipñun, un concepto que apareció en el mundo griego sólo a partir de la paz de Antálcidas; de ahí que SEager, considerando que «el primer intento consciente de transformar un tratado bilateral en vigor en una paz general es el que tuvo lugar tras 346, cuando se hicieron esfuerzos, según sabemos por Hegesipo, para extender la paz de Filócrates incluyendo a los demás griegos», hiciese hincapié

39. Así, Wade Geny, H. T., en Athenian Tribute Lists, vol. III, p. 279, nota 19. Atendiendo a la estructura del contenido a conferenciar Wüst, F. R. («Amphiktyonie, Eidgenossenschaft, Symmachie», Historia, III, 1954-5, p. 148), sólo veía en esta cláusula una invitación para discutir las medidas que permitieran mantener un efectivo estado de paz.

40. KEIL, B., Sitzungsberichte der Preuss. Akad. der Wissen., Leipzig, LXVIII, 1916, núm. 4, 2.

41. Tucídides V.48.2, 59.5, 76.3; Platón, República, 465 b; Andócides, III.20, 28, 40; Isócrates IV.106, 173; VII.1, 51; VIII.118; IX.61; etc.

42. Puede verse también el distinto significado en Demóstenes VI.36, VIII.4s., X.55 s. (más dudoso), IX. 17 s.; y una aparente excepción en XVIII.43. 
en que «it is... not only the wording of the clause which arouses suspicion - that might be explained as the product of fourth-century rewriting. The ideology which lies behind the proposal, the diplomatic conditions and techniques which would make it feasible, also seen to belong not to the fifth century but to the fourth» ${ }^{43}$.

$\mathrm{Y}$, realmente, el contenido del decreto se explica adecuadamente a la luz de las circunstancias históricas del siglo IV.

1. La aparente pretensión de Pericles de convertir la paz de Calias en una xotvì Eipñu y la importancia concedida al tema de la libertad del mar parecen implicar los años que transcurren entre la paz de Filócrates (346) y la renovación de la guerra con Filipo (341), ya que en los años cuarenta del siglo $\mathrm{V}$ a. C., las repercusiones que estas cuestiones poseían en los debates políticos atenienses eran de gran importancia, al

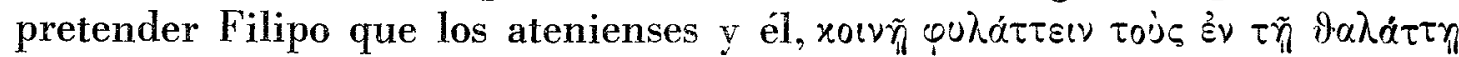
xaxouproũvtas. Desde luego, la aparición en estos años de un decreto atribuído a Pericles, en donde se pusiera de relieve el contraste existente entre la situación contemporánea frente a la del siglo anterior, habría supuesto un gran impacto propagandístico. Por ello, la elección de temas incluídos en el congreso, como motivo de debate, vendría determinada por lo que resultaba relevante en el contexto histórico en que se creó el congreso.

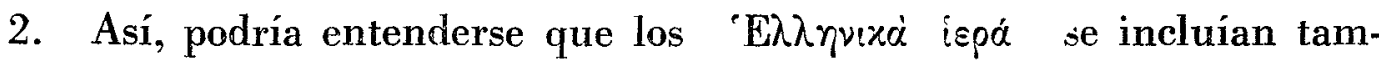
bién contrastadamente. Mientras que Filipo intervenía ahora en los asuntos de la anfictionía fócida ${ }^{44}$, Pericles aseguraba en el decreto la capitanía de Atenas en cuestiones relativas a los templos griegos. Y la indicación de Esquines en Пlề $\tau \tilde{\eta} \varsigma$ $\pi \alpha \rho \alpha \pi \rho \varepsilon \sigma \beta \varepsilon i \alpha \varsigma$ (114) puede ser significativa $^{45}$.

3. Asimismo, como desde 346 Filipo celebraba los festivales píticos - sin la presencia de Atenas que, por este motivo, se negó a tomar parte en ellos ${ }^{46}$ _, la alusión en el decreto a unos $\vartheta \cdot v \sigma \circ o i$, independientemente de su historicidad plausible en el siglo $\mathrm{V}$, serviría para patentizar que un

43. SEAGER, R., art. cit., p. 136 .

44. Cfr. Demóstenes V.14; IX.32; XIX.50, 111, 132, 181, 327.

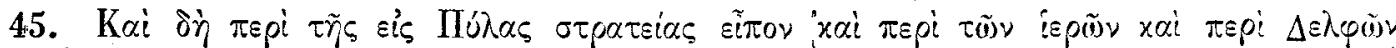

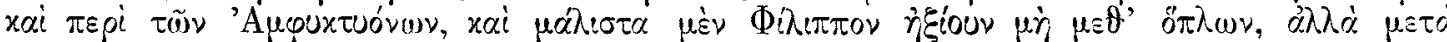

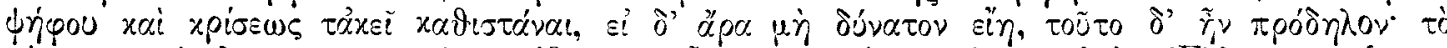

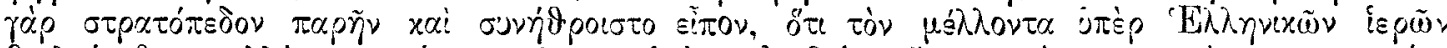

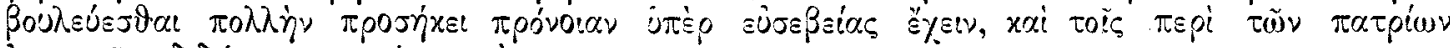

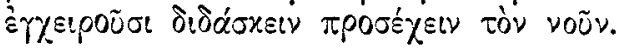

46. Cfr. Demóstenes V.22 y, sobre todo, XIX.32, 128. 
siglo antes Atenas se había encargado de organizar festivales de carácter panhelénico en conmemoración por las victorias de antaño sobre los bárbaros.

4. Es decir, todo el contenido del Congreso podría explicarse como una maniobra propagandística ateniense de carácter antimacedónico, y de ahí que se invitase a naciones de Grecia central, pues eran estratégicamente importantes para evitar la ingerencia de Filipo al sur de las Termópilas.

5. Sin embargo, resulta sorprendente que se haya inventado con estos fines un congreso que jamás tuvo lugar, según el propio testimonio

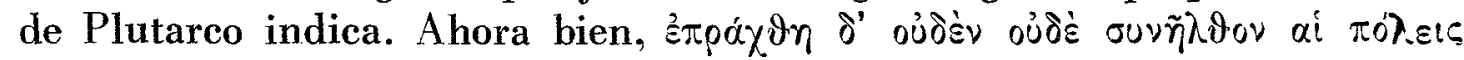

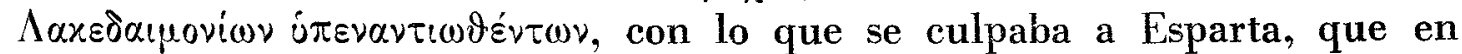
estos comienzos de la segunda mitad del siglo IV ya no poseía importancia política decisiva, pero que apoyaba a Filipo para recobrar parte de su pretérito poderio ${ }^{47}$.

6. En suma, «debió haber sido inventado entre 346 y $340 \ldots$ Ciertos aspectos del Decreto del Congreso se explican difícilmente si el documento es genuino; algunas características de su lenguaje y contenido suponen los rasgos ideológicos y las condiciones diplomáticas del siglo cuarto, en particular de los años 340. Una explicación a estos hechos podría ser que el decreto fue inventado en esta época» ${ }^{48}$.

Con todo, y a pesar de que la argumentación de SEAger es, en verdad, muy sugestiva, hay algunos puntos en que resulta poco convincente o, por lo menos, poco explícita. Cabe pensar, sobre todo, que, si el decreto se trata de una invención propagandística del siglo IV, algún orador lo hubiese mencionado con esa finalidad; sin embargo, hay un absoluto silencio al respecto. Desde luego, me parece que Meiggs no tiene razón al aducir como argumento contra la tesis de SEAGER que «an attempt that failed when Athens was the strongest power in Greece was not a good avertisement for a revival of the policy when she lacked adequate resources to give weight to her diplomacy ${ }^{49}$, pues precisamente lo que se trataría de poner de relieve sería un intento fallido, como advertencia para la situación contemporánea en la que los estados helénicos debían enfrentarse con todas sus fuerzas a Macedonia si no querían ver comprometida su libertad. Y, psicológicamente, la alusión a Esparta como causante del fracaso del congreso constituía un argumento reivindicativo para la Atenas que nuevamente volvía a tratar de erigirse en defensora de la

47. Cfr. Demóstenes V.18; VI.9, 13, 15, 19 ss.; Esquines, II.104, 133.

48. SEAGER, R., art. cit., p. 141.

49. Meiggs, R., The Athenian Empire, p. 514. 
independencia griega ante las maquinaciones de potencias extranjeras. Además, esa crítica de Meiggs resulta condicionada por su aceptación de la paz de Calias e intrínsecamente contradictoria con su visión de los hechos, pues si «the decree itself... is more important than the reason for its failure, and in the interval between the end of the war with Persia and the beginning of the rebuilding of temples it makes good historical sense» ${ }^{50}$, es indudable que el decreto en sí, unido al efecto propagandístico de la razón de su no realización, se explica con mayor propiedad en un contexto propio del siglo IV que en uno de mediados del siglo $\mathrm{V}$.

$\mathrm{Y}$, en cualquier caso, el análisis interno de su contenido permite el planteamiento de algunas consideraciones que deben afrontarse para el mejor conocimiento del problema relativo al congreso.

1. El silencio de Tucídides supone, ya de entrada, un obstáculo en contra de su autenticidad y no hay explicación convincente para el mismo, a no ser que le fuera por entero desconocido. $Y$, en este caso concreto, no es posible hallar a lo largo de toda su obra ni tan siquiera un indicio de qus, pese a conocerlo, lo mencione implícitamente, como pretenden los defensores de la paz de Calias respecto a VIII.5.5 y $56.4^{51}$

50. Meiggs, R., Ibid., p. 513.

51. NöLdeKe (Aufsätze zur persischen Geschichte, Leipzig, 3887, p. 53) pensó ya que Tucídides parecia estar sobreentendiendo el conocimiento de la paz por parte de sus lectores, al decir que los atenienses se negaron a que el rey navegara libremente por aguas griegas, pues, indudablemente, un tratado debía prohibírselo. La línea fue seguida por MEYER, E. (Forschungen zur alten Geschichte, Hildesheim, II, p. 77): «diese Verhandlung hat den wichtigstein Paragraphen des Kalliasfriedens zur Voraussetzung) y por Gomme, A. W. (A historical commentary on Thucydides, Oxford, 1945, I p. 332-333): (ssuch a demand, coming from one about to accede to a request, could only be based on a written agreement».

ANDrewes (Historia, X, 1961, p. 15) argumentó, tratando de justificar su hipótesis, de que Tucídides está aludiendo implícitamente a la paz, quc «possesion of the Asiatic coast... ought... to carry with it automatically the right to build and sail ships there, but in this case apparently does not, and the King's right to bring a fleet into the Aegean is the subject of a separate demand, distinet from his demand for the territory...). Pero creo que la exigencia persa a navegar en el ígeo no es indicio de dos cláusulas diferenciadas. Persia exigía la seguridad ateniense de que sus navíos no serían atacados; es decir, quería establecer la franquicia de comunicaciones entre las ciudades griegas de Asia Menor que volverían al seno del imperio si Atenas accedía a las demandas hechas por Alcibiades. Sin embargo, los atenienses se opusieron, probablemente porque no estaban dispuestos, aunque con tal de contar con el apoyo persa en la guerra iban a entregar los territorios jonios, a renunciar al dominio del mar. Y garantizar la seguridad a los navios del rey en el Egeo conllevaba el peligro de perder esa hegemonia. Además, si Andrewes concluye que «a satisfactory explanation would be that a previous treaty had denied the King the right to bring ships into the Aegean», hay que pensar que la autonomía de las ciudades griegas de Asia Menor iba a ser vulnerada por Atenas al acceder a las demandas persas, y este punto, según nuestros testimonios, pertenecía a un tratado entre Atenas y Persia 
Además, este silencio se amplía a todos los autores griegos, incluída la oratoria panegírica

2. El fragmento 153 de Teopompo ${ }^{52}$ (F. Gr. Hist., 115) me parece, asimismo, un testimonio importante para la discusión sobre el congreso, cuando se implica, junto al juramento helénico, un contenido indeterminado:

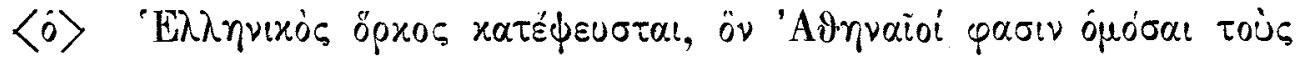

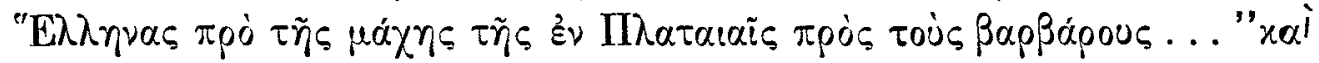
ö $\sigma \alpha \alpha \lambda \lambda \alpha "$, p

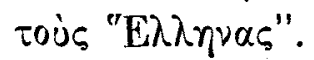

La importancia de este testimonio, determinante para la consideración de la paz de Calias, puede extenderse a la cuestión del congreso. Según el pasaje recogido por Elio Teón ${ }^{53}$, el historiador denunciaba la falsedad del juramento helénico pronunciado antes de la batalla de Platea, la paz de Calias, las inexactitudes en la descripción de la batalla de Maratón y, parafraseando, «todo aquello de que falsamente blasonan los atenienses engañando a los griegos». ¿A qué se refiere, pues, con $\delta \sigma \alpha \alpha \lambda \lambda \lambda \alpha$ ? Naturalmente, aducir que podría estar aludiendo al decreto del congreso es, a priori, inconsistente. Sin embargo, hay ciertos indicios en el contexto del fragmento que podrian sugerirlo.

a) El testimonio de Plutarco sobre el congreso presenta como primer punto de discusión el de los templos griegos que los bárbaros incendiaron, en tanto que el juramento helénico de Platea había acordado

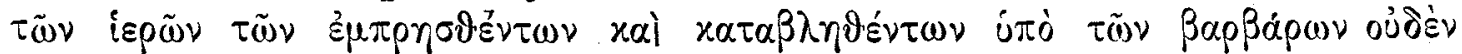

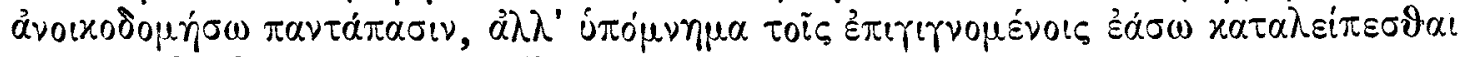

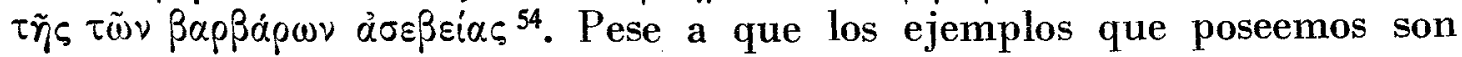
exiguos, se ha aducido que los templos destruídos en las guerras médicas

Y respecto a VIII.56.4, el propio Tucídides habla en repetidos pasajes de la libe-

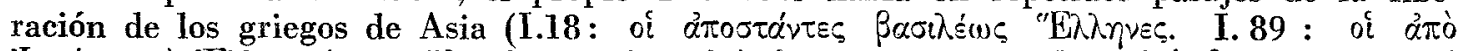

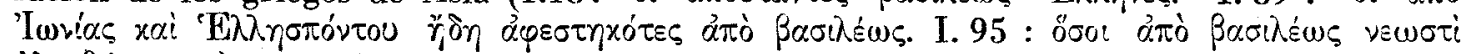
$\dot{\eta} \lambda \varepsilon \cup \theta \varepsilon ́ \rho \omega \nu \tau 0)$ y probablemente se hubiese expresado en otros términos si las ciudades de la alianza hubieran tenido que pagar también a Persia.

52. El fragmento entero dice: “De Teopompo, en el (libro) veinticinco de las Filipicas, (procede la noticia de) que el juramento helénico, que los atenienses dicen que pronunciaron los griegos antes de la batalla de Platea contra los bárbaros es falso; también el tratado de los atenienses [de parte de los griegos (?)] con el rey Darío (?). $\mathrm{Y}$, asimismo, (que) la batalla de Maratón no aconteció como todos ponderan y «de cuantas otras cosas blasona la ciudad de los atenienses y (con las que) engañó a los griegos).

53. En los Progymnasmata (ed. de Spengel, L., Rhetores Graeci, II, Leipzig, 1854), probablemente de finales del siglo I d. C.

54. Licurgo, Contra Leócrates 81. Diodoro en XI.29.3 da un texto casi similar que quizá indique común dependencia de Eforo. 
no fueron reconstruídos en los años inmediatamente siguientes ${ }^{55}$, por lo que se ha relacionado esta cláusula con la correspondiente a los templos en el juramento helénico; como si en realidad se tratase de una consulta, a los delegados de las ciudades que tomaran parte en el congreso, para tratar de si el juramento iba a ser mantenido o, por el contrario, en qué medida - si el objetivo de Pericles perseguía reconstruir templos atenienses_ podrían ser reconstruídos los templos sin infringir el juramento.

b) En este sentido, si el decreto se relaciona con el juramento de Platea, las palabras de Teopompo podrían estar implicando, igualmente, una denuncia del mismo.

c) El problema, entonces, viene suscitado por el empleo de $\dot{\alpha} \lambda \alpha$ -

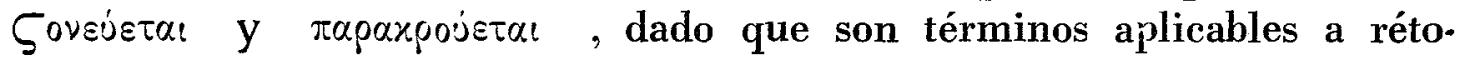
res ${ }^{56}$ y que todo el fragmento de Teopompo implica una denuncia contra exageraciones de la política ateniense del siglo $\mathrm{V}$ aparecidas en el siguiente. Pero su intención era patentizar que las exageraciones distorsionadas del pasado ateniense tenían lugar principalmente en discursos de oradores. Y si ello es así, la cuestión cobra ahora una nueva perspectiva, dado que no aparece una mención al congreso en ninguno de los testimonios forenses o panegíricos que se nos han conservado. Precisamente en este silencio de la oratoria ha basado Meiggs su crítica contra la hipótesis de SEAGER de que el congreso era una invención de lus años cuarenta del siglo IV, argumentando que «the strongest argument in favour of authenticity is the silence of the orators and historians. This could be explained if the decree was not inscribed on stone because it led no nothing» ${ }^{57}$, pues, de ser una falsificación propagandística, algún eco de esa propaganda tendríamos que hallar en la oratoria. Sin embargo, hay una evidencia que puede aclarar la problemática. Licurgo mencionó el juramento helénico en $331 / 330$ y la crítica de Teopompo es tal vez un decenio anterior al discurso Contra Leócrates ${ }^{58}$, lo que, junto al testimo-

55. Cfr. Dinsmoor, W. D., "Observations on the Hephaesteion», Hesperia, suppl. 5,1941 , pp. 156 y ss.

56. En la literatura del siglo IV tenemos suficientes pruebas: Isócrates, XII.20 y 271; Platón, Cratilo, 393 c; Jenofonte, Memor., I.7.5; Esquines, I.170.

57. Meiggs, R., The Athenian Empire, p. 514. Curiosamente, sin embargo, se sirve de este argumento para criticar la hipótesis de falsificacion pero no se plantea las causas del silencio de Tucídides. Cabría pensar en principio que Crátero hubiera descubierto el documento en los archivos del Metroon y que la oratoria lo hubiese ignorado. Pero, de ser cierto históricamente, es sospechoso que las fuentes contemporáneas del siglo $V$ no se hayan hecho eco.

58. Dado que Teopompo se había opuesto a la veracidad de la paz y que Calístenes en Plutarco, Cimón 13.4, implicaba una oposición a algo, los críticos contrarios a la realidad de la misma han tratado de hallar una posible relación de dependencia entre ambos, como respondiendo a una misma motivación. Dado, por otra parte, que dentro de su extrema concisión Teopompo se opone con un argumento exclusivamente técnico, ya desde Schwartz se ha hecho depender a Calístenes de Teopompo. Creo que, en 
nio de Diodoro sobre idéntico tema, demuestra que el orador no fue el primero en servirse del documento. Además, en 343, Demóstenes, en su

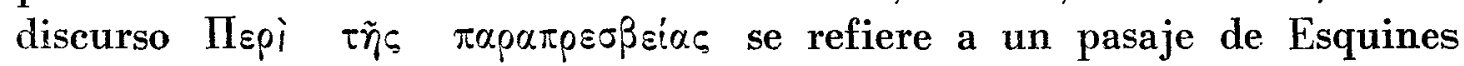
que no conservamos en el que, oponiéndose a Filipo tras la caída de Olinto en verano de 348 , citaba una serie de documentos que, como en el caso de la estela de Trecén, no eran genuinos del siglo V. Así, Demós-

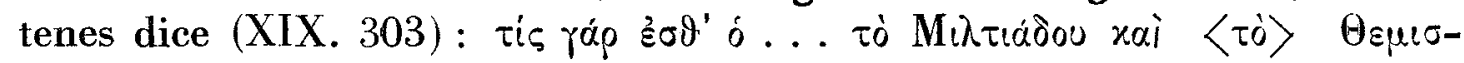

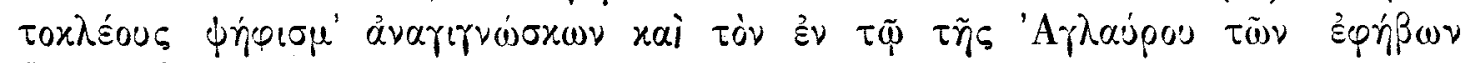
óprov; oủx oũtos; .

d) Es decir, que Esquines mencionaba en ese pasaje unos decretos, que no habían sido mencionados por la tradición anterior, con una finalidad claramente propagandística: conseguir que Atenas reaccionase con-

realidad, la crítica sobreestima en ocasiones la capacidad de información que un escritor antiguo podía tener de escritos coetáneos. Con todo, esta dependencia se debe a un error de interpretación: suponer que Calístenes niega la realidad de la paz y, como la objeción específica contra ella la formuló Teopompo, sostener que aquél adoptó su crítica influído por la de éste. Pero, en primer lugar, existen problemas cronológicos. Schwartz, aunque nadie aceptó su hipótesis, propuso que Calístenes debió haber conocido los argumentos de Teopompo, por lo que el pasaje en que habla de ella y que vería Plutarco debía hallarse en la Historia de Alejandro, obra posterior a la publicación del libro veinticinco de las Filipicas de Teopompo (ScHwartz, E., "Kallisthenes Hellenika), Hermes, XXXV, 1900, p. 109: “Kallisthenes knüpfte die Leugnung des Vertrages an eine Schilderung der Schlacht am Eurymedon: für eine solche Schilderung ist kein leichterer Anlass denkbar, als Alexanders Marsch durch Pamphylien im Jahr 333. Damals, vermutlich schon vor 334 , müssen von Theopomps philippischen Geschichten mindestens die ersten 25 Bücher veröffentlicht gewesen sein»).

La hipótesis me parece en principio viable, ya que al hablar de la marcha de Alejandro a través de Panfilia una mención a la batalla del Eurimedonte sería explicable (cfr. Connor, W. R., Theopompus and fifth-century Athens, Cambridge, Mass., 1968, pp. 86 y 172, nota 30 , acerca de la posible inclusión de la digresión sobre la paz en

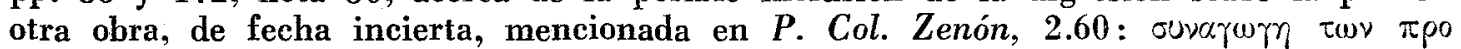

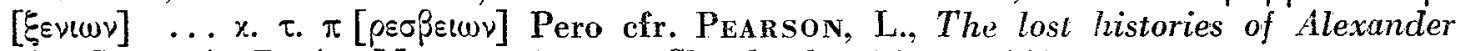
the Great, A. P. A., Monographs, 20, Cleveland, 1960, p. 29).

Ahora bien, si Calístenes hablaba de la paz en las Helénicas, que es anterior a las Filipicas de Teopompo, no podría depender de éste y su oposición al tratado no estaría condicionada por el historiador de Quíos (cfr. MEYER, Forschungen, II, p. 4 y 5 con un intento de reconstrucción del comienzo de las Helénicas. Cfr. también JacoBy, F., R. E., s. v. Kallisthenes (2), Band X, col. 1696). Naturalmente, para un defensor de la paz esto supone un doble problema, pues si Calístenes depende en su negativa de Teopompo, sólo tiene que tratar de justificar la de éste; en cambio, si es anterior, ya son dos los autores que muestran oposición independiente a explicar. Por eso WadE GERY ((The peace of Kallias), Essays in Greek History, Oxford, Blakwell, 1958, p. 204; a partir de F. Gr. Hist., 69, fr. $1=$ Epist. Socr., 30.14 y F. Gr. Hist., 72, fr. 20.1, adoptó una posición intermedia que resulta notoriamente forzada: cuando Calístenes escribió durante el reinado de Filipo sus Helénicas podía conocer ya el argumento de Teopompo, aunque el libro veinticinco de las Filipicas no se publicara antes de la muerte de Filipo, ya que es posible que dos panfletos antiatenienses, que Teopompo insertó en los libros décimo y vigésimocuarto de las Filipicas, fueran publicados separadamente.

En todo caso, creo que el conocimiento de la objeción de Teopompo por parte de Calístenes no es un problema de capital importancia, pues éste no se está oponiendo a la realidad de la paz, sino a sus cláusulas como denota $\tau \alpha \tilde{u} \tau \alpha$ en el texto de Plutarco. 
tra Filipo tras la cuestión olintia rememorando sucesos aducidos como ciertos, acaecidos ejemplificadoramente durante el siglo V. HABICHT ${ }^{59}$ hizo hincapié en que, a la vista del amenazador peligro que representaba Macedonia, en Atenas desempeñaron un importante papel, en las discusiones internas de la disposición de la ciudad frente a Filipo, una serie de documentos referidos a relaciones entre griegos y persas que sólo aparecen mencionados a partir de mediados del siglo IV, es decir, posteriores en cien o ciento cincuenta años al tiempo originario a que se referían y cuya investigación revela, en general, falsedad histórica, salvo quizá en el caso del juramento de los efebos atenienses ${ }^{60}$. De ahí que «Theopomps Polemik ist verständlich genug; es erbitterte ihn, dass die Agitation gegen seinen Helden (i. e., Filipo) mit gefälschten Dokumenten geführt wurde, die diesen zugleich auf eine Stufe mit den persischen Barbaren stellte» ${ }^{61}$.

e) Por su contenido, el decreto del congreso presenta concomitancias con todos aquellos que el crítico alemán enumera ${ }^{62}$ : se refiere en parte a hechos relacionados con las guerras médicas; y, asimismo, en él Atenas aparece como conductora de la política griega. Bien es cierto que Teopompo en el fragmento 153 sólo se opone claramente al juramento de los helenos y a la paz de Calias; y, probablemente, al Pséfisma de Milcíades en lo relativo a la presentación exagerada de la batalla de Maratón. Pero es indudable que su $x \alpha i$ ö $\sigma \alpha$ $\alpha \lambda \lambda \alpha$ etc., implica su conocimiento de otras cuestiones semejantes, es decir, decretos falsificados en el siglo IV que la oratoria presentaba como genuinos del $\mathrm{V}$.

f) Y si el problema fundamental estribaba en el silencio de los oradores, habría que dilucidar en toda su amplitud si ello es determinante. Quizá en este punto se halle la causa de algunos de los problemas que suscita el testimonio de Plutarco sobre el congreso.

3. Plutarco no menciona su fuente de información para esta cuestión, de ahí que se haya suscitado el interrogante de si el decreto tuvo

59. HABicht, Chr., «Falsche Urkunden zur Geschichte Athens im Zeitalter der Perserkriege», Hermes, LXXXIX, 1961, pp. 1-35.

60. Registrado por Demóstenes (XIX.303, 311-312) y Licurgo, Contra Leócrates, 76-77.

61. HABIcHT, art. cit., p. 14 .

62. Cronológicamente: Pséfisma de Milcíades de 490 a. C. para enfrentarse a los persas en Maratón (p. 20); pséfisma de Temístocles de 480 acerca de la evacuación de Atenas (pp. 1-10); pséfisma de los trecenios de 480 en torno a la acogida de los fugitivos atenienses (pp. 20-21); pséfisma de la bulé ateniense de 479 en Salamina para deliberar sobre la oferta de Mardonio (pp. 21-22); juramento de los helenos de 479 (p. 12, nota 2); pséfisma de 479-8 sobre la estatua del hiparco Xápuos en la Acrópolis (p. 23); pséfisma sobre la atimía de Artzmio de Zelea - un agente persaen todo el territorio de la alianza, datable entre 470-450 (pp. 23-25); paz de Calias (pp. 25-26); juramento de los efebos atenienses (p. 12, nota 1), éste con problemas. 
una primera manifestación epigráfica o literaria. Y pienso más bien en un origen literario para su testimonio. Es cierto que algunos aspectos de su exposición muestran semejanzas con decretos tradicionalmente fechados en el siglo $V$, como vimos que ocurría en lo relativo al envío de mensajeros y a la edad de los mismos; pero, asimismo, hay indicios de que el contenido se mueve en términos del siglo IV - lo que descartaría una procedencia del siglo anterior- y en bases literarias.

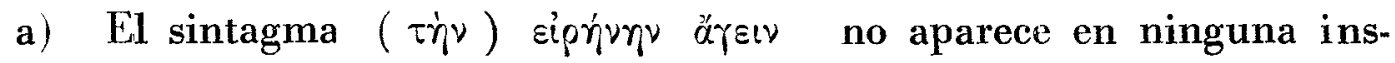
cripción de esos siglos.

b) En un contexto exclusivamente ateniense el término $x \alpha i$ $\mu \varkappa \rho \alpha \dot{\nu}$

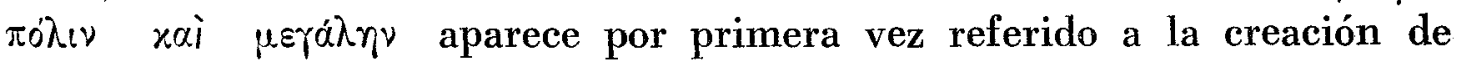
la segunda confederación marítima ${ }^{63}$.

c) La igualdad declarada de todos los griegos (el congreso debía

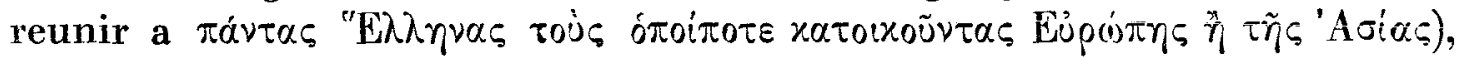
sin distinción entre europeos y asiáticos, no aparece patentizada hasta los inicios del siglo IV ${ }^{64}$.

d) El texto implica ya el concepto de Kotv่ Eiprivn, que no apa-

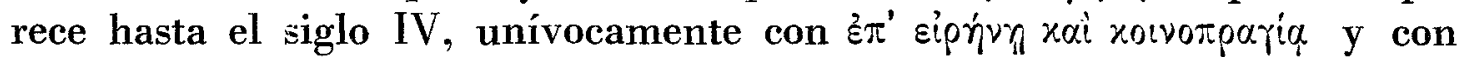

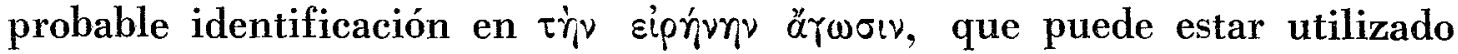
sin el significado de «una paz determinada», sino más bien bajo el concepto de paz en general.

4. En todo caso, no hay que descartar la posible existencia de una estela en la que constara el decreto, pero que no sería, naturalmente, genuina del siglo $\mathrm{V}$ y que, a mi juicio, no aparecería, si existió, en la colección que reunió Crátero. A este respecto me parecen importantes las palabras de Plutarco en 17.4 cuando explica que el congreso no se reunió por la oposición lacedemonia is $\lambda_{\varepsilon} \gamma_{\varepsilon \tau \alpha !}$; es decir, está registrando algo que en su opinión no es absolutamente cierto o comprobado, quizá porque disintiese de su fuente literaria, que sería el sujeto de $\lambda \varepsilon ́ \gamma \varepsilon \tau \alpha_{\ell}$. En cambio, en Cimón 13.5 aduce el testimonio de Crátero en contra del juicio de Calístenes sobre las cláusulas de la paz ${ }^{65}$. Pienso, entonces, que

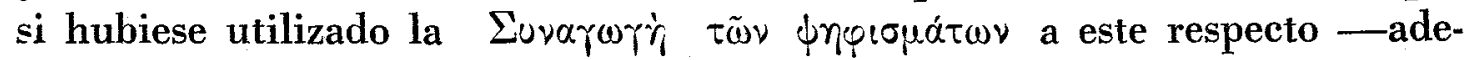

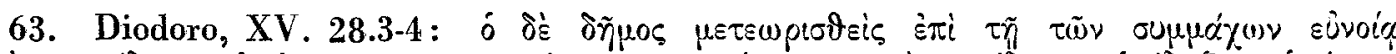

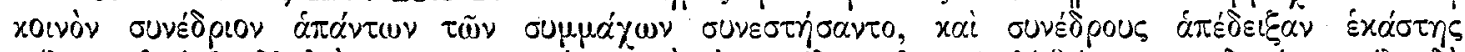

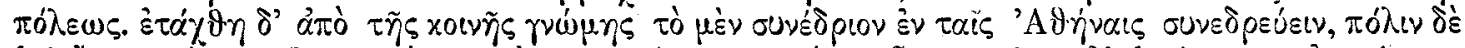

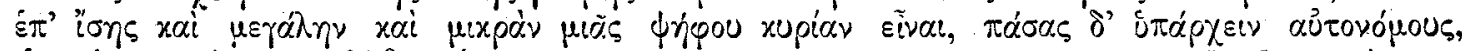

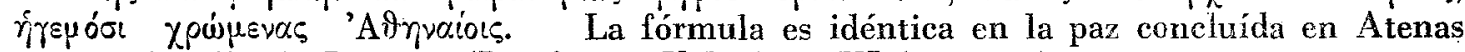
tras la batalla de Leuctra (Jenofonte, Helénicas, VI.5.1 y ss.).

64. Así, la demanda de Agesilao de que las ciudades de Asia deben ser autónomas,

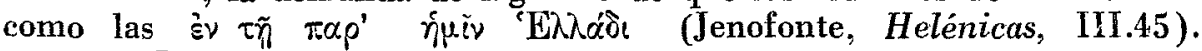

65. JACOBY, F., F. Gr. Hist., 342, fr. 13. 
más de una fuente literaria-, hubiese explicitado la opinión de Crátero alli expuesta, ya fuera coincidente con su fuente literaria o divergente. Las posibilidades me parecen así reducidas a una sola: Plutarco se sirvió tan sólo de una fuente literaria, pero no de una epigráfica, que en ningún caso fue Crátero.

5. Ahora bien, ¿cuál fue la fuente literaria de que se sirvió para esta información? El que su testimonio presente ciertos rasgos propios de los decretos inscritos en piedra creo que implica una fuente oratoria. Indudablemente, no tiene por qué tratarse del discurso no conservado de Esquines en que mencionaba los decretos de Milcíades, Temístocles y el juramento de los efebos, pues en principio plantea problemas que Esparta resultase mencionada negativamente como causante del fracaso del congreso. Pero puede tratarse ocasionalmente de algún orador perteneciente al círculo de políticos radicalmente nacionalistas y antimacedónicos, en un discurso que no nos ha advenido, semejantemente a lo ocurrido en el Pséfisma de los Trecenios, que fue citado por Hipérides

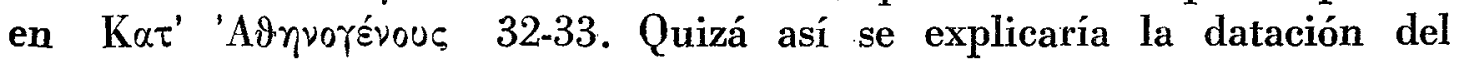

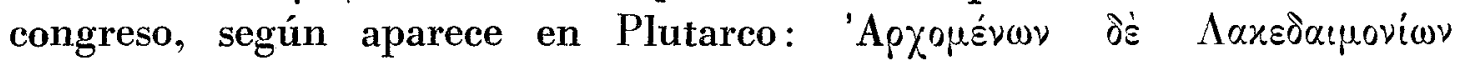

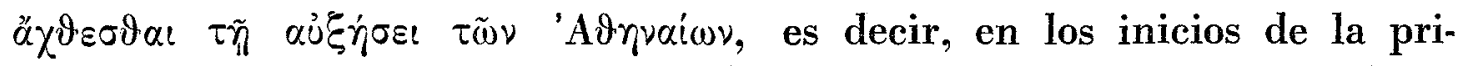
mera guerra peloponésica (461-460), ya que así aparecería en el comentario de su fuente acerca del congreso, que el biógrafo seguiría punto por punto, aunque expresando sus dudas respecto a la actitud espartana. Naturalmente, se entiende de esta manera que el texto de Plutarco posea rasgos propios de los decretos grabados en piedra junto con anacronismos e incongruencias: el ఛiṇ cles no era originario del siglo $\mathrm{V}$, sino una invención propagandística del IV. 


\section{ApÉndice}

También Plutarco, en Pericles, 12.1-3, es un importante testimonio para la discusión de la paz de Calias y, desde luego, quien sostenga su autenticidad histórica debe explicar este pasaje. En él, el biógrafo describe la oposición de los adversarios políticos de Pericles a la política constructora de este último, planteando la estructura del pasaje la sucesión de acontecimientos en tres niveles:

1. Planteamiento de la cuestión (12.1) : la actividad constructora de

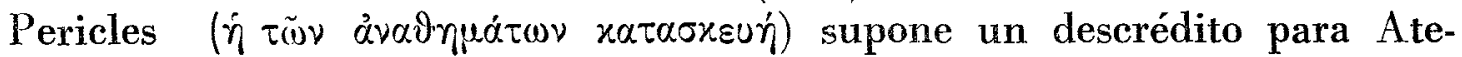
nas al haber traído de Delos el tesoro de la confederación marítima

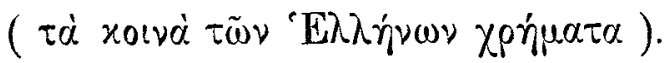

a) Si el pretexto aducido para ello era el temor a una posible intervención persa, se ha puesto ahora de manifiesto la falsedad del mismo

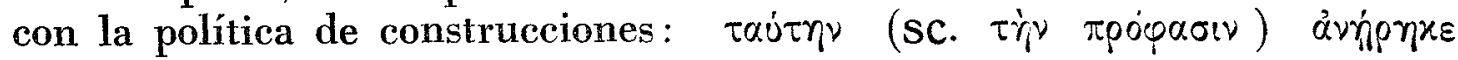
$\Pi \varepsilon p\llcorner\lambda \lambda \tilde{\eta} s$.

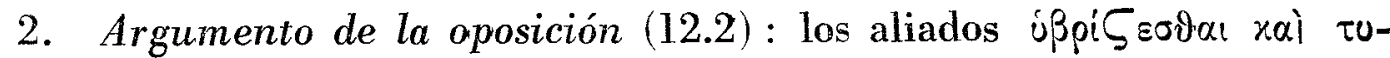

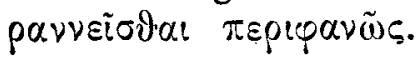

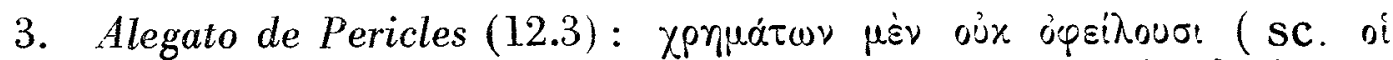

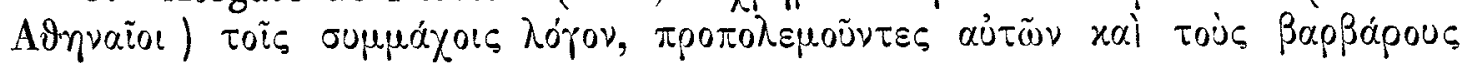

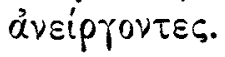

Sin duda, el debate sobre el empleo que daba Atenas al dinero aliado debió tener lugar entre 454, fecha en que las reservas de la confederación se depositaron en el tesoro de Atena (cfr. Diodoro XII.38.2 y Plutarco, Aristides, 25.2), y 447/446, en que comenzó la construcción del Partenón (con evidencias epigráficas en $I G, I^{2}$. 339-362, sobre concesiones y pagos por parte de los tesoreros. PritchetT ( The transfer of the Delian Treasury», Historia, XVIII, 1969, pp. 17-21) ha apuntado recientemente la hipótesis de que la transferencia del tesoro puede datarse con anterioridad a 454, pues, además de que nuestros testimonios literarios no permiten establecer una cronología segura, la documentación epigráfica -en 454 comienzan las listas fiscales - no informa sobre el traslado, solamente permite inferir que en ese año ya se había verificado. En todo caso, una

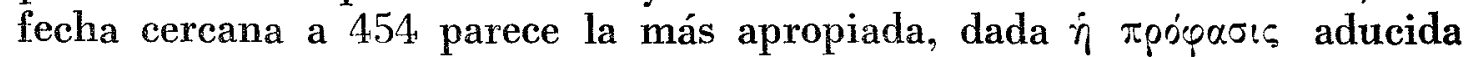

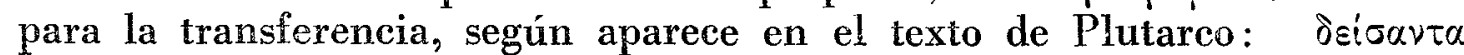

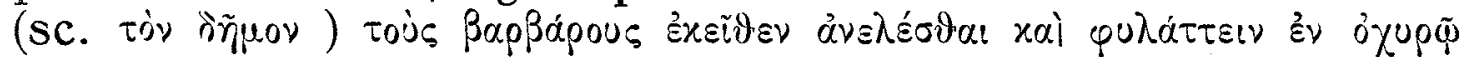
$\tau \alpha \dot{~}$ xolvá, una argumentación que tendría pleno sentido tras el desastre ateniense en Egipto, acaecido precisamente en ese año (cfr. Tucídides, I.110) y que pudo suscitar en Atenas el temor, cierto o fingido, de una posible contraofensiva persa en el Egeo.

Pero, sea cual sea la fecha precisa del traslado del tesoro de la confederación, es indudable que el debate registrado por Plutarco debió tener 
lugar en fecha próxima al comienzo del Partenón. $Y$, pese a ello, todo el pasaje del biógrafo parece estar implicando la inexistencia de la paz tradicionalmente fechada hacia $449 / 448$. Y ello por varias razones.

1. Plutarco presenta un estado de cosas que indican que la guerra contra Persia seguía vigente cuando tuvo lugar la discusión que registra.

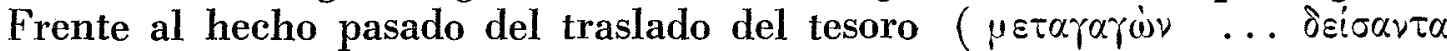

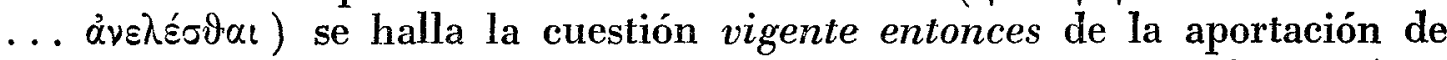

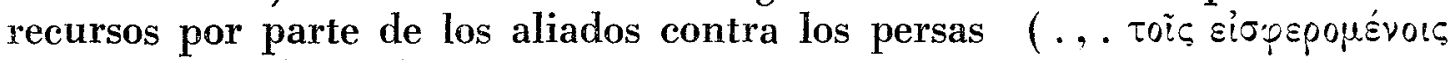

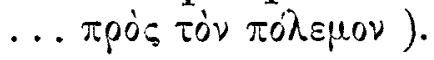

2. El propio Pericles (12.3) alega que los aliados no tienen por qué pedir explicaciones sobre el uso que Atenas hace de las contribuciones

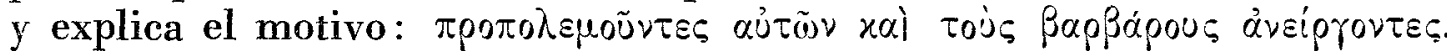
Es decir, está reconociendo que la guerra contra Persia continúa; al menos, no cabe otra interpretación a partir del texto griego. Y creo que resulta, dentro del valor que posee todo el pasaje, muy importante para

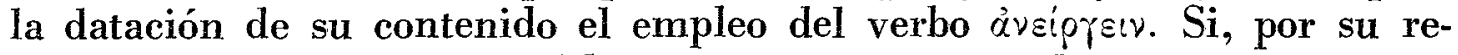
lación con el programa perícleo de construcciones, el pasaje es posterior a la muerte de Cimón, el significado del verbo estaría aludiendo a la segunda campaña de éste en Chipre, que habria supuesto para Atenas, independientemente de su mayor o menor éxito militar, la confianza en sus propias fuerzas tras la intranquilidad que debió despertar en

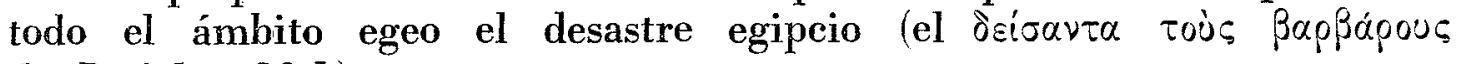
de Pericles, 12.1).

3. Busolt (Griechische Geschichte bis zur Schlacht bei Chaeroneia, Gotha, 18932, III, p. 349, nota 1 y p. 357, n. 1, en oposición a A. Sснм IDT, Perikl. Zeit., I, 283 y II, 225, para quien el tratado de Calias no era una verdadera paz, sino un acuerdo de demacación militar que debía crear por tiempo indefinido un modus vivendi) adoptó, ante esta evidencia, una solución de compromiso, ya que para él «der Vertrag wurde wharscheinlich nicht schon im Jahre 448 , sondern erst ein oder zwei Jahre später abgeschlossen»; lo cual no está de acuerdo con la cronología tradicional, que data la paz inmediatamente después de la muerte de Cimón, y no constituye sino un intento por paliar el peso de la evidencia de Plutarco.

Además, junto a esta presencia del empleo de participios en presente, hay que tener en cuenta otra consideración. Si la paz hubiese sido conocida por los adversarios políticos de Pericles, esperariamos que la hu-

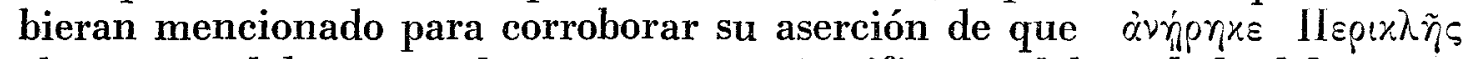
el pretexto del temor a los persas como justificante del traslado del tesoro. Naturalmente, no cabe pensar en un silencio deliberado por parte de Plutarco, ya que en Cimón 13.4-5 admite la existencia de la paz y de las objeciones de Calístenes a su contenido. La cuestión dẻ̉e concretarse en la fuente que pudo utilizar para este pasaje. Y en este punto, como en tantos otros, nada puede afirmarse con seguridad; y, aun hipotéticamente, las posibilidades de error son numerosas. Meiggs (The Athenian Em- 
pire, pp. 139-140) ha pensado que tal vez pudiera tratarse de lón de Quíos, pero, además de la imposibilidad de identificación, el problema de la fuente de Plutarco plantea, en todo caso, problemas similares a los suscitados por éste

1. Fuese cual fuese la fuente, en ella no aparecería mencionada la paz en el pasaje de la oposición a Pericles. Aquí cabe entrever una doble posibilidad, pero que no modifica la conclusión sobre el problema:

a) Que la fuente de Plutarco fuese del siglo V (Helánico, Estesímbroto, Ión de Quíos u otro).

b) Que fuese posterior (un atidógrafo del siglo IV - como Clidemo, Androción, Fanodemo u otro- o una fuente posterior, aunque esto me parece menos factible).

En el primer caso el desconocimiento de la paz en una discusión semejante resulta en extremo sospechoso y suscita una duda más sobre la existencia de la paz de Calias. En el segundo caso, el problema puede afrontarse desde una doble perspectiva igualmente sospechosa.

a) Que esa fuente del siglo IV, o posterior, de la que se sirviera Plutarco, no conociera la paz - o, al menos, no la mencionase en ese contexto, algo incomprensible-; pero esto supondría la existencia de un testimonio, desconocido para nosotros, que no se haría eco de la tradición panegírica sobre ella y la cuestión derivaría hacia implicaciones de tipo negativo, como en el caso de Teopompo.

b) Que esa fuente hubiese utilizado una anterior, con lo cual tendríamos un problema similar al apuntado anteriormente.

2. Si pensamos que la fuente pudo haber sufrido una ampliación retórica durante su transmisión y que Plutarco la halló con esa configuración - para justificar así el empleo de las formas temporales en presente-, la conclusión resulta igualmente negativa: de acuerdo en que,

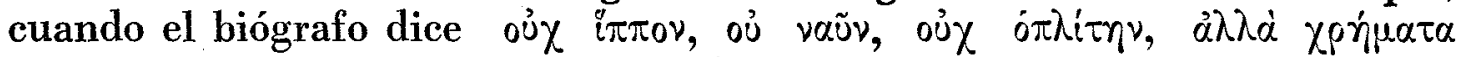

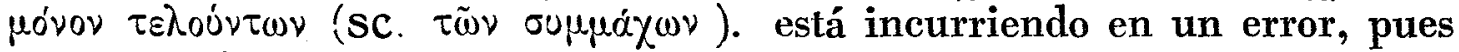
en la batalla naval de Egina y en la terrestre de Tanagra aparecen tropas aliadas combatiendo junto a las atenienses (455 y 456 a. C.), pero ello no debe suponer sino una generalización de un estado de cosas extendido a la mayoría de los aliados, salvo excepciones, más que un argumento retórico. $\mathrm{Y}$, en todo caso, si «the long and detailed analysis of the social and economic advantages of a public-works policy, with its carefully balanced clauses, reads more like the fourth than the fifth century», o si «the whole section may indeed have approached its present form in the late fourth century when Athens had again embarked on a public-building policy» (MEIGGS, ibid.) vuelve a suscitarse la misma pregunta que en el apartado anterior: ¿no sería presumible que el argumento del empleo del dinero aliado para ornato de Atenas se hubiese visto reforzado con el de la acusación a Pericles de estar en paz con Persia? Naturalmente, podría 
alegarse que este motivo no sería quizá utilizado en el siglo IV como una acusación, dado el carácter que adquirió la paz; pero ello sería concebible en otro contexto que no fuese un ataque contra la política períclea. Algo semejante podría haber sucedido en un texto panegírico.

3. Finalmente, el crítico inglés ha apuntado la posibilidad de que este pasaje de Plutarco respondiese en realidad a una ficción retórica, apoyándose en la contradicción existente entre los testimonios de Cicerón (De Oratore, II.93; Bruto, 27) y Quintiliano (III.1.12, XII.2.22 y XII.10.49), sobre la existencia o inexistencia de discursos atribuíbles en su época a Pericles, y en lo que dice el propio Plutarco en Pericles, 8.7,

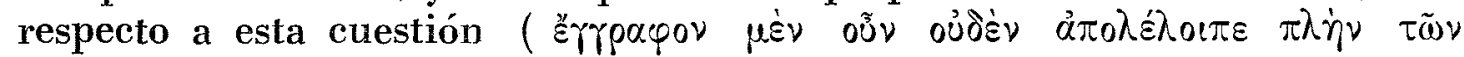

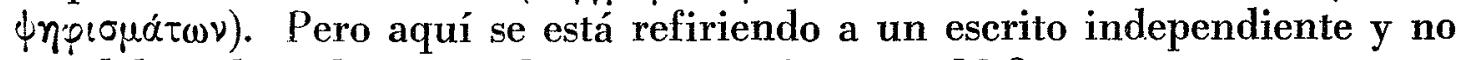
a palabras literales como las que menciona en 12.3 .

En todo caso, no veo por qué podría considerarse este testimonio de Plutarco sobre el debate de la política constructora una ficción retórica y no así su información sobre el congreso panhelénico. El planteamiento de su testimonio sobre la oposición política en Atenas a Pericles resulta por completo inteligible y responde a ulteriores manifestaciones atenienses en pro de los aliados, como las reiterativas de Aristófanes, por ejemplo.

A mí, al menos, este testimonio de Plutarco me parece realmente sintomático. Y si hay que pensar en ficción retórica, eso es algo que más conviene a la paz de Calias; por lo menos desde el punto de vista del objeto. En cualquier caso, el que cuando tuvo lugar este debate la guerra con Persia siguiera en pie y no se mencione la paz en un momento inmejorable para haberlo hecho, permite concluir con STockTon («The peace of Callias», Historia, VIII, 1959, p. 70) que «if we are to take Plutarch's participles seriously... then we must either abandon Wade Gery's reconstruction of the sequence of events at this time, or else we must accept that there was no formal peace concluded between Athens and Persia, at least until after the announcement of Pericles' building programme». Es decir, que hacia 447 la paz no había tenido lugar todavía. 
